\title{
Administração e Produtividade
}

EURICO REZENDE

$\mathrm{O}$

tema que nos conduz a esta honrosa intervivência tem, sem dúvida, as suas raizes principais adentradas nos canteiros da natureza e do programa do DASP.

Com efeito, quando se procura enfocar, no ângulo público, o binômio Administração e Produtividade, a vigilância de nossa atenção há de conectar-se, sobretudo, com a politica de recrutamento e de aperfeiçoamento de pessoal, de envôlta com tôdas as conseqüências e implicações a ela inerentes.

Organizar para progredir, eis o lema que deve enflorar o ideal dos paises vocacionados para a emancipação nacional e o respeito internacional.

Sem desenvolvimento científico, não há desenvolvimento técnico. nômico.

Sem desenvolvimento técnico, não há desenvolvimento ecnsocial.

Sem desenvolvimento econômico, não há desenvolvimento

Sem desenvolvimento social, não há estabilidade politica.

Dai, então, compreender-se, tranqüilamente, o papel fundamental do vosso Departamento, eis que os padrões cientificos $e$ técnicos da comunidade funcional são os instrumentos válidos, sem os quais a improvisação, a inoperância e a perplexidade ainda continuarão, no perpassar de longos anos, a negar liberação à plenitude de nossas potencialidades materiais e culturats.

Inobstante, o DASP vem sendo impedido de, integralmente, realizar a seriedade das metas que a lei the confiou, no que concerne ao contrôle da politica de pessoal capaz.

Nesse sentido, a estatística oficial revela esta verdade mil vêzes maldita: apenas $10 \%$ do nosso funcionalismo civil constituem safra decorrente de concursos.

Paradoxalmente, a hostilidade ao sistema do mérito tem partido do Congresso e, algumas vêzes, do próprio Poder Judiciário, e sempre com a conivência omissiva (decurso do decêndio sem manifestação) ou ativa (sanção) do Poder Executivo. 
Tudo isso se fêz, e desbragadamente, apesar de as Constituições brasileiras, a partir da de 1934, determinarem rigidez seletiva na admissão de servidores, salvante a ocorrência transitória da Carta de 1946, plenamente justificável, porque ali se tratava de uma benemerência decretada em momento alto e jubilar da vida nacional.

Durante nosso processo histórico e político, temos assimilado a alternação de bons e maus exemplos norte-americanos.

Por quê, então, na abrangência da imitação, não importamos, por exemplo, o método tradicional, no que respeita ao funcionalismo, seguido, inflexivelmente, pela grande nação do norte?

Ali, em 1960, o Poder Executivo possuia 2.398.705 cargos. Dêsse quantitativo, 2.050.939 foram providos através do sistema do mérito, atingindo, por via de conseqüência, quase $90 \%$ de aproveitamento seletivo.

Hoje, no Brasil, o mérito vive, como dissemos, na casa, melhor seria dizer, na choupana de $10 \%$. Mais do que êsse percentual, os Estados UInidos já possuíam em 1884, época dos nossos avós, e do nosso Império.

Não se entendam essas observações como reconhecimento da frustração ou da inoperância do DASP. Entenda-se, tão-sòmente, como um desencanto, pois a sua magnitude $e$ as suas realizações se constituem numi constâncla do aplauso público e da prestação de heróicos serviços à Nação. Mas se o altiplano institucional dêste Pais se houvesse submetido, nestes trinta anos, à hierarquia dos mandamentos constitucionais, sua obra teria sido completa e teríamos alcançado um melhor estágio de civilização administrativa.

Todos devemos estar convictos, porém, agora de que uma nova era surquiu para a dignificação do serviço público, em têrmos de sistema de mérito.

O nôvo comando constitucional reproduziu os preceitos congêneres das Cartas proscritas. E o fêz de modo severo, através das disposicões claras e peremptórias dos artigos $95, \S 1^{\circ}, 99, \S 1^{\circ}$. E foi além, inovando: federalizou a exiânncia saneadora. impondo as normas seletivas, expressamente, aos Estados e aos Municipios, consoante sentencia o art. $13, \mathrm{n}^{\circ} \mathrm{V}$.

Convém ainda ressaltar que a jovem Constituição liquidou as históricas resistências ao sistema do mérito. que privilegiavam as instituicões parlamentares e judiciárias, onde ocorriam os festivais de clubes fechados em matéria de criação de cargos, exasperação de vencimentos e vantagens e realejo de livres nomeaçöes.

Daí porque seja-nos licito proclamar que a nova Constituição do Brasil se apresenta, também, como uma valiosa oferta de ferramentas inoxidáveis ao DASP para a consecucão dos seus altos objetivos de aperfeiçoamento da Administração Pública. 
Dentro do tema que nos propusemos, procuraremos analisar e dimensionar as implicações da administração e da produtividade, como ciências.

Não podemos considerar simplesmente a primeira como sendo a ação de administrar, ou gestão de negócios públicos e privados; nem considerar a segunda como sendo a proporção entre uma produção adicional e o capital empregado para acarretar esta produção.

Noutros têrmos, conforme definição de alguns economistas, a produtividade expressa o grau marginal de intensidade de capital. Conseqüentemente, temos que ir mais além em conjecturas e análises, pois o conceito de ad́ministração é amplo e pràticamente envolve tôdas as ciências humanas, a pura e as exatas, e pode, em sintese, ser assim definido: administração é a efetivação de realizacões em todos os campos da atividade humana.

No que tange à administração como ciência, podemos atirmar que o seu êxito depende, em grande parte, da intuição, da seleção e do treinamento do pessoal empregado na execução de tarefas específicas. A propósito, merece invocado o pensamento de BEARD: "Se entendermos que a ciência é algo que nos habilita a atribuir valôres matemáticos às particularidades observadas $e$, em conseqüência, a exprimir os resultados através de equações diferenciais, a Administração não será uma ciência. Sob êste ponto-de-vista, talvez a astrofísica pudesse ser considerada ciência; mas convém lembrar que as leis mecânicas do Universo nada nos dizem sôbre a côr e a composição das estrêlas, nem conseguiram, até agora, explicar, satisfatòriamente, distúrbios e explosões que parecem acidentais.

Se, entretanto, empregarmos a palavra ciência tendo em vista um conjunto de conhecimentos derivados da observação $e$ da experimentação, formando um sistema de regras cuja aplicabilidade a própria experiência haja demonstrado, permitindo, inclusive, efetuar previsões, poderemos, então, falar em Ciência da Administração".

Já se perdeu na poeira do passado o conceito no sentido de que a Ciência da Administração é pertinente, exclusivamente, à Administração Pública. Administração é, òbviamente, gênero, e administração pública é espécie dêsse gênero. conforme Fayol demonstrou no II Congresso Internacional de Ciências de Administração, em Bruxelas, no ano de 1923.

Algumas pessoas supõem que a Ciência da Administração é aplicável à Administração Pública; outras, que é sòmente aplicável à Administração de Emprêsas. Taylor, entretanto, espancou a controvérsia, ao afirmar no início do século: 
"Esperamos que os leitores compreendam que êstes princípios podem ser aplicados, com resultados satisfatórios, a tôdas as formas de atividade humana, desde a economia doméstica às questões mais complexas de administração das várias instituições que as necessidades da vida social criaram, como a exploração de fazendas, a direção de casas de comércio, grandes ou pequenas, a administração de igrejas, de instituições filantrópicas, de universidades e ao funcionamento dos serviços públicos."

O âmbito de aplicação das novas técnicas, apoiado na Ciência da Administração, é, pois, irrestrito.

Da mesma forma que um engenheiro, aqui, diante dos senhores, teria condições de falar sôbre os sistemas de contrôle e reavaliação do rendimento do trabalho dentro da sua construtora. poderia o médico discorrer sôbre a administração e a produtividade no setor hospitalar.

Enfim. tanto a administração com a produtividade são ciências vinculadas, pelas suas implicações, com as demais ciências que se conhecem, das quais não podem prescindir como meio para sua estruturação e desenvolvimento.

No Brasil, de 20 anos a esta parte, busca-se fazer administração em moldes científicos, notadamente no que concerne à realização de metas sócio-econômicas.

Exemplo dêsse nôvo estágio é o Programa Estratégico do atual Govêrno, iá elaborado e cuja vigência trienal terá início em 1968.

Sôbre êsse documento, que exprime as diretrizes da Administração planejada, pretendemos acionar nossos comentários.

A estratégia oficial ali proposta visa a associar administração e produtividade. Mas essa tarefa vem sendo dificultada nnor fatôres diversos, sobretudo o período de decisiva transição que se opera no País, as pressões sociais solicitando a drenaqem de recursos técnicos e financeiros para o desenvolvimento e êste suhordinado às limitações decorrentes do combate à renitência inflacionária.

Como ponto de referência, partimos da premissa de que qualauer plano é bom, desde aue os princínios que norteiam a assistência econômica seiam efetivamente válidos dentro da realidade que se procura afetar e explorar.

Para isso, os responsáveis pela elaboração do projeto, antes de efetuar os esboços preliminares, tiveram o cuidado de nesquisar a realidade brasileira, para que tão-sòmente a verdade e a franqueza presidissem aos objetivos básicos, às diretrizes de politica econômica e ao programa estratégico.

Planos, estudos e trabalhos práticos exigem administração nbietiva, como, também, um esfôrço organizado por pessoas que tenham estabelecido o que deva ser feito e como fazê-lo. 
Podemos considerar que o programa de ação do atual Govêrno foi estabelecido de modo que terá um efeito determinante. muito além dos limites que podem ser calculados em têrmos numéricos de fábricas, estradas, centrais elétricas e outros itens de suas listas setoriais e regionais. Nenhum pais pode adaptar-se ao atual mundo mecanizado, sem transformar tôda sua estrutura social e administrativa, como foi postulado pelo titular do Ministério do Planejamento.

Não falta nesse Plano o estôrço que deve ser despendido em favor do aperfeiçoamento individual, pois sòmente assim é que podemos almejar uma transformação duradoura na vida do nosso povo.

Não é novidade que quase todo projeto de desenvolvimento econômico produz, de certo modo, uma "reação em cadeia", e sua execução estimula automàticamente $o$ povo a novas atividades produtivas. Seria acaciano dizer que mais e melhores estradas propiciam transportes mais baratos e mais rápido e eficiente escoamento para os mercados de distribuição e consumo, com o aumento das safras, e que havendo eletricidade ocorre um desdobramento vigoroso de usos e aplicaçôes em beneficio geral.

Há outras oportunidades, nem sempre bem compreendidas. São os casos em que se impõem novas técnicas de raciocinio administrativo para execução de determinadas tarefas. Nesta etapa do desenvolvimento brasileiro, vale destacar as lições diuturnas que nos são dadas pelos dedicados técnicos do DASP, através de contribuições que nem sempre afloram às vozes do rádio, nem às colunas da imprensa ou às imagens da televisão, mas se diversificam no complexo processual da administração pública .

Dentro dos propalados "sistemas auxiliares de administraک̧ão", em que a documentação e os atos praticados são padronizados, vem se pautando o atual Plano Estratégico, ao estabelecer um exame sistemático à experiência e projetos, a fim de se chegar a tipos mais ou menos padronizados de plantas e construções apropriadas às condições locais e aos tipos de produtos industriais mais indicados para uma multiplicidade de emprêsas e outras pequenas unidades nas zonas rurais, como também nos arrabaldes dos setores urbanos, tipos êstes que são aceitos universalmente.

Em sintese, a idéia central que inspira todos êsses propósitos visa, de uma forma efetiva, ao desenvolvimento global da comunidade, objetivando, iqualmente, o circuito completo ao amplo desenvolvimento da indústria em pequena escala, em contraposição às fábricas centrais em. larga escala. E para isso foi integrado ao Plano um conjunto de diretrizes, pelas quais a iniciativa governamental pode mobilizar uma vasta receptividade local, colocar a reserva de mão-de-obra de subemprêgo e estimular o 
empreendimento individual em potencial, uma das formas mais autênticas do investimento nacional, que, dentro da atual estratégia, toma a forma de planos complementares e integrados, e são os seguintes:

1. Tipos e planos padronizados para emprêsas industriais locais de pequeno porte, suplementados de serviços de assessoria, relacionados principalmente com indústrias que são locais por sua própria natureza e satisfaçam uma necessidade indispensável em todo o Pais.

2. Tipos e planos padronizados para o desenvolvimento da construção de casas.

3. Tipos e planos para os serviços de irrigação para aquelas áreas sob administração direta das superintendências do desenvolvimento econômico.

4. Tipos e planos para os serviços gerais da administração municipail.

5. No que se refere ao item anterior, o Govêrno se propõe a mobilizar a mão-de-obra local para investi-la no desenvolvimento de capital disseminado pela zona rural, de um tipo que vá ao encontro das necessidades conhecidas das mesmas pessoas que fornecem o trabalho. Por êste meio, criar mercado para produtos industriais; ampliar o incentivo local para a construção de fábricas; orientar êsse incentivo através de serviços de assessoria, e encorajá-lo através de instituições creditícias; difundir experiências e treinamentos em melhores padrões de trabalho e de vida.

6. No setor privado: aumento da liquidez das emprêsas; diminuição do ritmo de expansão dos custos e aumento de demanda.

Nota-se, então, que entre as linhas de ação oficial se busca uma cuidadosa programação de investimentos, o aumento da eficiência do setor público e a redução da pressão exercida sôbre o setor privado.

Tais metas só poderão ser alcançadas evitando-se, com o auxílio de uma técnica administrativa vigilante e consciente, a pulverização de recursos; reduzindo-se os custos e elevando-se a produtividade, para o que poderá desempenhar papel decisivo a Reforma Administrativa de fevereiro dêste ano; e aliviando-se, progressivamente, o impacto tributário e de outros gravames na produção e na comercialização.

O plano, sem dúvida, tem efeitos equísticos, isto é, tem efeitos econômicos diretos e indiretos, pois refere-se ao homem, em relação ao seu meio e à sua economia.

$\mathrm{Na}$ fase de sua preparação, coletaram-se informações corretas sôbre os recursos humanos e naturais do País. Feita a radiografia, partiu-se para as prioridades. Vários estágios podem ser 
destacados sob êsse título. Em todos êles são inevitáveis alguns conflitos entre os diversos setores da economia ou entre os diversos ministérios. Mas a flexibilidade do Plano permitirá, sem delongas ou dificuldades, as medidas corretivas, evitando-se, assim, as parturbações setoriais ou globais.

A tônica das prioridades estabelecidas reside, principalmente, na melhoria da produtividade industrial e agricola e na construção de estradas e centrais elétricas, que constituem itens interligados em qualquer programa de desenvolvimento econômico.

Ao preparar o Plano, cuidou-se de dar ênfase à importância e ao papal a ser desempenhado pelas emprêsas públicas e privadas nacionais. E, pela primeira vez, se ressalvou que a ajuda externa terá apenas uma função suplementar.

Convém destacar que outro objetivo prioritário do esquema de linhas de ação é o alargamento de oportunidades, capaz de absorver o adicional-ano de um milhão de pessoas, que é o crescimento da mão-de-obra no Brasil.

Teve-se em vista equacionar as dificuldades gerais de todo o pais em des`nvolvimento, mercê dos recursos financeiros escassos, que são fatôres qeradores de incerteza na planificação. Considerou-se a falta de pessoal especializado e o Govêrno já se preocupa em mobilizar os cientistas brasileiros que se encontram no exterior, procurando criar condições para o seu retôrno e intenração no trabalho nacional. Avançou-ce nas coniecturas de análises micro e macro-econômicas, com o nlaneiamento de tôdas as medidas adeauadas, inclusive a mobilizacão interna de fontes de canital nara o desenvolvimento, desemperrando a máquina de arrecadacão fazendária, tı. is isco pautado num certo graú de minúcias nos estágios preliminares.

Quanto à execução, confiamos no seu êxito, assequrado péla flexihilidade dos seus meios, instrumentos e usos. O Ministério do Planejamento, agora, em virtude da Reforma Administrativa, é um óraão de estruturação efetiva e o seu entrosamento com os demais Minictérins ficou comprovado, harmôniçmente. com a preparação do Plano, que recebeu a assistência de todo o complexo qovernamental.

Em muitos paises, estas tarefas específicas de contrôle do desenvolvimento ficam a cargo do Ministério da Fazenda e noutros estão na subordinação direta do qabinete do Primeiro Ministro, como acontece nas nações socialistas e comunistas.

No Brasil, a orientação posta em prática foi a da criação de um Ministério separado, cabendo a êste a coordenação das propostas dos Ministérios executivos e cotejá-las, juntamente com os seus próprios planos, buscando-se uma esquematização global do desenvolvimento na fôrça dos recursos disponiveis.

Fora de dúvida a importância da organização administrativa nos rum 's da produtividade, notadamente quando se fala em di- 
retrizes de Govêrno voltadas para a retomada do desenvolvimento.

O reconhecimento desta verdade e a ampliação dos encaryos e das responsabilidades da técnica administrativa nesta quadra da vida brasileira podem ser medidos e avaliados pelas amplas solicitações da jovem Constituição de 24 de janeiro. Através do nôvo Estatuto, a União chamou a si o poder normativo da tributação principal para os Estados e os Municipios; sub-rogou-se na tarefa de executar planos regionais de desenvolvimento; instituiu a figura do orçamento-programa; deferiu ao Estado federal a faculdade de criar regiões metropolitanas, e erigiu, em fator básico, o orçamento plurianual.

Essas inovações são desafios a uma administração bem aparelhada, de modo a que, assegurando a produtividade, possa o País tirar o rendimento máximo dos empreendimentos programados, sem perder de vista a necessidade inadiével de realizar a atenuação inflacionária.

O após-guerra constituiu, em verdadeira mistica, o esfôrço pela produtividade, valendo citado o exemplo da Françá, onde, a partir de 1949, êsse instrumento válido de desenvolvimentu deixou de ser manejado apenas pelos técnicos de administração, para empolgar engenheiros, empresários, economistas, sociólocos e politicos, graças ao que a comunidade funcional e operária dêle adquiriu a conscientização geradora do progresso multiplicador.

No campo da terminologia, embora LiTTRÉ a tenha definido, há setenta anos, como a faculdade de produzir, a produtividade distingue-se da produção, e, segundo alguns, até fundamentalmente. fica.

Na realidade, a noção de produtividade é uma noção cientî-

A produtividade surge, assim, como a base mais sólida das ciências sociais. e não se esqota on se reáliza no simples esfórco físico do trabalhador ou na canacidare meramnte burocrática do funcionário. Depende, sim, das condições naturais, da formação científica e profissional do técnico, do sel1 "know how", das máquinas e do instrumental aue têm ao seu alcance, das ferramentas, da enerqia mecânica utilizada e de um série de outros elementos, que vão surqindo ao lonnn da execução de um trabalho, de um investimento ou de uma obra.

Já aue a produtividade é uma variável motriz aue enqendra o desenvolvimento econômirn, não poderia, necessàriamente, deixar de ser considerada no Pronrama Estratécico do Govêrno. E ai se contém o apêlo constante à colaboração da comunidade.

Podemos afirmar, com base em fatos concretos, que a produtividare é a meta principal do atual Govêrno em direção do bem-estar social. 
A prova $d_{a}$ assertiva está em que se nega, terminantemente, a alteração da política salarial, instituida por lei, inobstante as rogativas e as reivindicações visando à sua reformulação.

E que as autoridades governamentais, sempre atentas ao comportamento inflacionário, estão convictas de que só pelo in cremento da produtividade, vale dizer, somente pela conquista do adicional da produção, terão meios para aumentar o poder aquisitivo dos assalariados.

Assim, no seu próprio interêsse, devem os trabalhadores se empolgar pela produtividade.

"A politica governamental em vigor assegura a manutenção do salário real médio dos trabalhadores, permitindo sua elevação na proporção do aumento da produtividade. Isso significa, de um lado, que o poder aquisitivo médio dos assalariados não se reduzirá, mesmo durante a fase de contenção da inflação, e, de outro lado, que os frutos do desenvolvimento serão imediatamente partilhados pelos trabalhadores, na mesma proporção em que se eleva a eficiência do sistema econômico", segundo o pensamento
oficial.

Qualquer outra medida não passará de otimismo paisagistico, inteiramente discricionado da realidade, que é uma afirmação irrevogável, por isso que assentada na ciência e na técnica
de administração.

No plano da reestruturação administrativa para o aumento da produtividade, vemos que o meio de maior hierarquia e poder decisório é a assistência científica. E o pensamento, assim elaborado nas oficinas da tecnologia, terminará por ingressar no clima da comunidade, realizando uma mentalidade a serviço de novos métodos de eficiência no serviço público.

E para que cheguemos à plena interação da produtividade em todos os setores, é necessário - antes de produzir - refletir sôbre o que vai produzir, qual o plano a executar e qual o destino a ser dado ao conjunto de bens ou serviços, de envolta com a aferição de sua valia, utilidade e uso no complexo sócio-econômico.

Com o auxilio da administração científica, êste jovem País de dimensões continentais deixará de nos oferecer as contradições entre a grandeza das suas potencialidades e o engatinhar do seu desenvolvimento.

Podemos apagar aquela imagem penosa de desigualdades, dentro da qual contemplamos a estatística desafiante, no sentido de que um agricultor americano alimenta 20 pessoas; um lavrador francês alimenta 10 pessoas e um agricultor brasileiro alimenta
apenas 12 .

Realizemos, sem tardança, a organização científica do trabalho, tendo, como exemplo, o paradigma, a Administração Pú- 
blica, integrada por elementos especializados, de mérito testado no regime da competição.

O Ministério do Planejamento e o DASP, se entrosados através de um sistema de vasos comunicantes, poderão institucionalizar, estimular e orientar a metodologia cientifica da Administração, visando a uma politica de produtividade, quer no serviço público, quer na atividade privada, disciplinando e incrementando o desenvolvimento econômico e social.

Esta é a vez. Esta é a oportunidade impar, eis que a Constituição de 1967, erigindo e consagrando, nas diretrizes do Estado Moderno, o Executivo forte, deu a êste quase a exclusividade e o arbítrio na formulação dos planos e na condução dos negócios do Pais, pois o Legislativo perdeu, e muito, a prerrogativa de iniciativa das leis e a faculdade de alterar as proposiçōes que são presentes ao seu exame e deliberação. Ficou-lhe apenas o direito de discordar com a palha das palavtas e nem sempre com - grão dos fatos.

Encerrando, coloco diante de vossa consciência e da vossa meditação o conceito lapidar do saudoso John Fitzgerald Kennedy:

"O espírito de produtividade é, pois, uma mentalilidade que consiste em substituir pelo ideal de pesquisa o hábito de imitação; pelo espírito crítico construtivo o espirito passivo; pela experiência concreta, o raciocínio; pela objetividade empírica, a autoridade da competência e do conhecimento científico. A produtividade ê a grande esperança do século vinte. Nos paises socialistas e capitalistas, procura o homem, no progresso técnico, o caminho de sua libertação."

Discurso proferido pelo Senador Eurico RezENDB - Diretor da Faculdade de Administração de Emprêsas do Distrito Federal - no $2^{\circ}$ Ciclo de Conferências sôbre Problemas de Administração em face da evolução tecnológica e de liderança, em Brasilia, no dia 18 de outubro de 1967. 